\title{
DURABILITY AND MEASUREMENT UNCERTAINTY OF AIRTIGHTNESS IN EXTREMELY AIRTIGHT DWELLINGS
}

\author{
Wolf Bracke $^{1}$, Jelle Laverge ${ }^{* 1}$, Nathan Van Den Bossche ${ }^{1}$ and Arnold Janssens ${ }^{1}$ \\ 1 Ghent University \\ Jozef Plateaustraat 22 \\ 9000 Gent, Belgium \\ *Corresponding author: e-mail address
}

\begin{abstract}
In this paper we present a series of leakage tests on extremely airtight dwellings $\left(\mathrm{ACH}_{50}<0.6\right.$ upon completion) in which the durability of the airtightness and the measurement uncertainty involved are assessed. In literature, repeatability and reproducibility issues have been discussed by several authors, along with influences of weather. It remains unclear, however, to what extent the available uncertainty intervals are relative or absolute. With the current tendency towards extremely low leakage levels and the introduction of airtightness requirements in building codes, the further exploration of this issue has become crucial.

In this paper, 4 aspects are studied consecutively: the repeatability and reproducibility of the fan pressurization method in extremely airtight houses, the impact of weather conditions on the measurements, the impact of the age of the construction and the reproducibility of the airtightness level in repeated construction of virtually identical houses. The latter is limited to short term effects since all dwellings $(n=15)$ were completed after 2010 .

The results show similar relative repeatability and reproducibility intervals to those found in literature. The rather large effects of weather conditions reported in previous studies could not be reproduced. Normal wear and tear due to occupation of the dwelling proved to introduce substantial relative deterioration of the airtightness of the building shell (20-100\% increase in leakage), although in absolute values, the additional leaks were modest and the buildings remained very airtight. In general, we conclude that pressurization tests render robust results in extremely tight construction, but with respect to ambitious leakage limits, test conditions and small preparation details such as the locking of window hardware can easily determine whether the dwelling will pass or fail.
\end{abstract}

\section{KEYWORDS}

Blowerdoor, reproducibility, durability, uncertainty

\section{INTRODUCTION}

Given Europe's ambitions to cut down $\mathrm{CO} 2$ emissions, all new-built houses will need to be constructed as nearly zero energy buildings by the end of 2020. While the public and building industry is well aware of the need for well-insulated buildings, there is still much room for improvement in terms of airtightness. In Belgium, for example, the median leakage level of standard construction in 2010 was just under $6 \mathrm{ACH}$ at $50 \mathrm{~Pa}$ pressure difference (Laverge et al., 2010), about 10 times as much as the limit imposed by the Passive Haus Institut to obtain the passive house certificate $\left(\mathrm{ACH}_{50}<0.6\right)$. 
Since new standards are emerging and maximum air leakage limits are imposed in energy performance codes, the need for a reliable test method and reliable results is growing. Although the European standard EN 13829 (CEN, 2001) describes the preparation of the building and explains in detail how the measurements should be performed, there still is room for interpretation. In Belgium, some of this ambiguity has been addressed in a separate guideline for tests within the framework of the official Energy Performance of Buildings (EPB) calculation (2013), but a number of issues are very case dependent and decisions on how to deal with them have to be taken by the tester on site.

The growing (financial) consequences of the result of a blowerdoor measurement put increasing stress on the reliability of these tests, especially in extremely airtight construction. In these cases, a modest absolute difference in leakage can make a large difference relative to the very low leakage limit imposed. Having well-trained test operators, reliable equipment, clear standard regulations and calculation methods are evident prerequisites for reliable results. Even if all the above conditions are met, measurement uncertainties will occur due to the effects of wind and temperature or the specifics of the installation of the equipment. It's important to be able to estimate and evaluate these uncertainties in order to compare test results and to define maximum wind speeds during the test.

It's also important to study the long-term variation of air leakage. Do blowerdoor test results remain stable during the changing seasons? If not, how big is the variation that occurs? Is this variation uniform for all building methods? What's the relation to the prevailing climate? Should airtightness parameters be corrected for these seasonal effects to obtain an objective result? And for the project-owner: when is the best time to test?

Besides seasonal effects, air barriers, like all building components, may be subject to degradation due to wear and tear, resulting in a rise in the air leakage after some years. It's essential to evaluate which materials or elements are responsible for this rise in order to build future houses with a more durable airtightness barrier, as well as to estimate infiltration losses over the course of the buildings lifespan.

In addition to the reliability and reproducibility of test results, the increasing stress, with the attached financial liabilities, on tight construction also intensifies the need for data on the reproducibility of the leakage level of a construction itself. How robust is the leakage level achieved by a specific construction method?

This paper addresses these issues with respect to houses at passive house leakage levels, since these represent the lowest $10 \%$ of the tested leakage rates included in the official EPB database in Belgium (De Baets and Jonckheere, 2013) and can therefore be considered to be representative for future airtight construction. In the next section, reproducibility issues of the pressurization test are discussed. The third section addresses the impact of weather conditions, while the fourth looks at the evolution of the leakage level over time. The reproducibility of the construction method is dealt with in the last section, followed by a conclusion section that sums up all results. For all tests a Minneapolis blower door type 4.1 was used.

\section{TEST REPRODUCIBILITY}

\subsection{Literature}

A number of studies available in literature give an idea of the expected variation when performing airtightness measurements.

A study by Delmotte and Laverge reported a standard deviation of $1,4 \%$ and maximum variation of $4,0 \%$ for 10 pressurization tests under repeatability circumstances (same operator, same test equipment) (Delmotte and Laverge, 2011). These numbers increased to $2,7 \%$ and $7,9 \%$ under reproducibility circumstances (different operators, different test equipment). 
Persily performed 28 pressurization tests on a house during a three-month period and found a $5,5 \%$ standard deviation and 19,4\% maximum variation (Persily, 1982). When only retaining the results from relatively calm weather days $(<2,5 \mathrm{~m} / \mathrm{s}$ wind speed) these statistics decreased to $1,7 \%$ and $4,8 \%$, showing the high impact of wind speed on the repeatability of pressurization test results. High wind speeds seem to be correlated with higher leakage results.

Kim and Shaw studied the air leakage from a house during a one-week period. They noticed similar results as the previous researches: a standard deviation of 1,7\% and maximal variation of 4,2\% (Kim and Shaw, 1986). The highest air leakages were measured during low wind speeds, in contrary to Persily's findings.

\subsection{Measurement results}

The repeatibility of the pressurization test was studied on 2 passive houses in Belgium. Passive houses are currently the only buildings subjected to maximum airtightness levels $(\mathrm{ACH} 50<0,6 \mathrm{~h}-1)$ and can be regarded as 'a look in the future' of the housing market.

House 1 is a semi-detached house, built in a traditional way using masonry walls. 48 pressurization tests with identical setup were performed on 7 different days in a 5 month period between December 2012 and April 2013. On average, the measurements showed a standard deviation of $1,1 \%$ and a maximum variation of $3,5 \%$ within the same day (Table 1 ). The mean leakage measured in all tests was $230 \mathrm{~m}^{3} / \mathrm{h}$ at $50 \mathrm{~Pa}$ pressure difference, corresponding to $0.54 \mathrm{ACH}_{50}$.

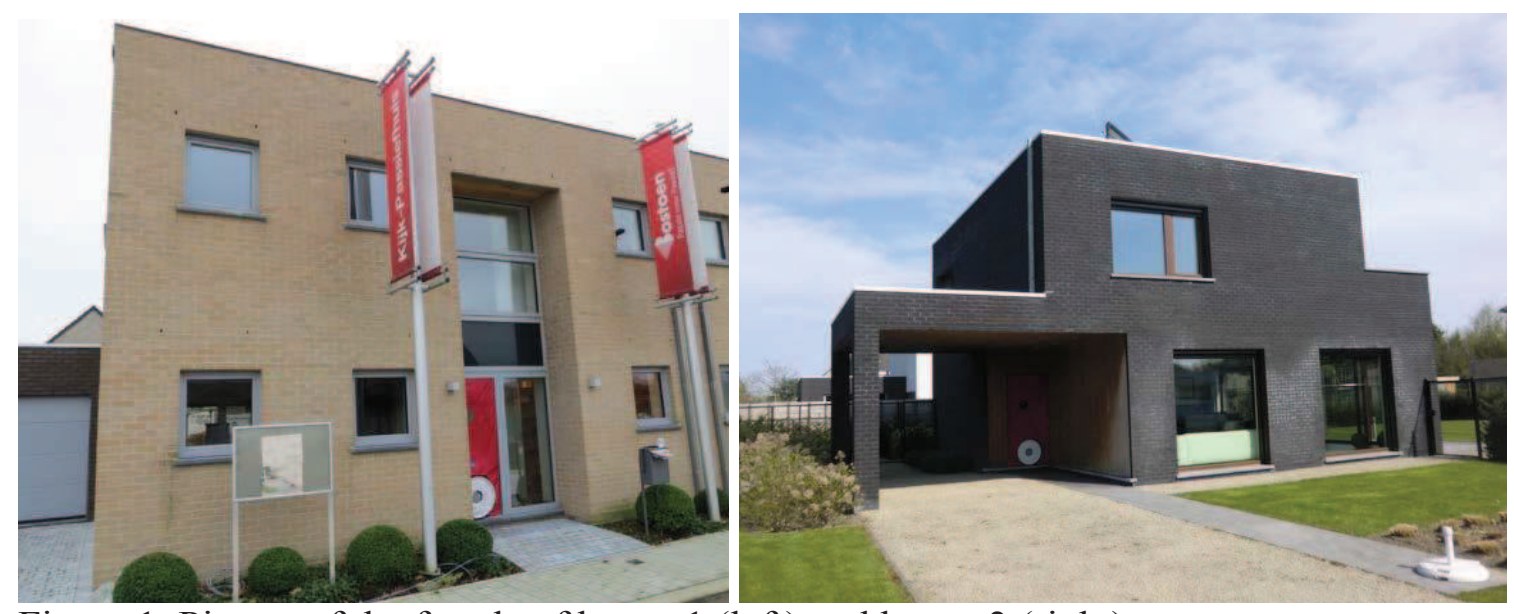

Figure 1. Picture of the façade of house 1 (left) and house 2 (right)

House 2 is a detached house with a wood-frame structure. It was tested 44 times in total, on 6 test days within the same period as for House 1 . Here, the variation within the same day was higher with an average standard deviation of $2,7 \%$ and an average maximum variation of 7,7 $\%$. These uncertainties are well in line with those reported in literature. When absolute values are considered, the average standard deviation within a test day is 3.2 and $3.5 \mathrm{~m}^{3} / \mathrm{h}$, for house 1 and 2 resp., suggesting that the error due to repeatiblity might be more absolute in nature than relative, although Murphy suggests that, in contrast, the error is relative to the square of the leakage (Murphy et al., 1991) and Delmotte did not find a clear correlation (Delmotte and Laverge, 2011).

No relation between wind speed and air leakage could be discovered, but the results on windy days show generally more variation. Wind speeds were derived from online weather observations, which are not always reliable. A mobile weather station would be a much better option to monitor wind speed and direction. 
A few additional tests were performed, to evaluate the effect of decisions in building preparation or test procedure - without neglecting EN 13829.

Table 1: Overview of air leakage measured in house 1.

\begin{tabular}{|r|r|r|r|r|r|}
\hline & \multicolumn{1}{|l|}{ date } & \multicolumn{1}{c|}{$\mathrm{V}_{50}\left(\mathrm{~m}^{3} / \mathrm{h}\right)$} & \multicolumn{1}{|c|}{$\mathrm{ACH}_{50}(-)$} & \multicolumn{1}{c|}{ stdev (\%) } & max var (\%) \\
\hline day 1 & $17 / 12 / 2012$ & 221.7 & 0.52 & 1.39 & 4.06 \\
\hline day 2 & $7 / 01 / 2013$ & 219.8 & 0.51 & 1.18 & 4.32 \\
\hline day 3 & $29 / 01 / 2013$ & 229.3 & 0.54 & 1.13 & 3.49 \\
\hline day 4 & $19 / 02 / 2013$ & 223.2 & 0.52 & 1.05 & 2.69 \\
\hline day 5 & $11 / 03 / 2013$ & 241.4 & 0.57 & 1.03 & 4.35 \\
\hline day 6 & $9 / 04 / 2013$ & 246.2 & 0.58 & 0.92 & 1.83 \\
\hline day 7 & $29 / 04 / 2013$ & 248.7 & 0.58 & 0.49 & 1.41 \\
\hline
\end{tabular}

As different pressure differences over the building envelope exist due to wind and temperature effects, the place of the external pressure point might influence the measurement results. Pressurization tests were performed on both passive houses, while changing the external pressure tap around the building. Although t-tests showed no significant difference between different positions of the pressure tube in most cases, we can't conclude that this effect is negligible. Probably the effect is masked by the usual variation in airtightness measurements.

Despite well-trained test operators, reliable equipment, clear standard regulations and calculation methods, pressurization tests will always show some uncertainty due to changing natural pressure differences around the building. As wind fluctuates constantly in speed and direction, natural pressure differences across the building envelope also change. External reference taps and baseline pressure corrections are intended to cancel out these fluctuations and thereby obtain reliable test results. For this to work, however, the external reference tap should be in the 'open field'. In actual measurements, this is often impossible to achieve because of the presence of all kinds of objects around the dwelling that create wind induced turbulences.

The results of consecutively executed natural pressure difference measurements within a total time span of 5 minutes reported in Table $22_{2}$ show that even 30 -second averages can change substantially in a short period of time, with a difference of more than $8 \mathrm{~Pa}$ over 5 minutes for the south facade. Baseline pressures, measured before and after a pressurization test which typically takes 20-30 minutes, are therefore not per se representative for the natural pressure difference during the test and can lead to false corrections.

Testing at high pressure differences reduces the impact of these changing boundary conditions and, renders more robust results, as was clearly demonstrated by Delmotte (Delmotte and Laverge, 2011).

Generally, the fan should be installed in the most airtight opening of the building envelope. As this is difficult to evaluate without performing multiple tests, the test operator will use the front door in most of the cases. But when the front door is leaky, this leakage is of course not included in the measurements. In house 2, measurements were performed on both doors, showing a decrease by $22,3 \mathrm{~m}^{3} / \mathrm{h}$ (or $15,5 \%$ ) when the fan was installed in the back door.

Standards give no clear indication whether doors should be locked during the pressurization test, or just closed, without turning the key. As leaks around doors can be almost eliminated by locking the door in case a multi-fix hardware is available, this decision can have a substantial impact on leakage results. In house 2, not locking the front or back door during a test led to an increase in leakage by $40,2 \mathrm{~m}^{3} / \mathrm{h}$ and $41,2 \mathrm{~m}^{3} / \mathrm{h}$. As the overall leakage in these 
dwellings is very low, this resulted in a relative increase of the total leakage of $33,4 \%$ and $28,9 \%$ respectively.

Table 2: consecutively measured 30-second averaged natural pressure differences at north, east and south facades for house 1.

\begin{tabular}{|r|r|r|r|}
\hline & \multicolumn{1}{|l|}{ North } & \multicolumn{1}{l|}{ East } & \multicolumn{1}{l|}{ South } \\
\hline measurement 1 & -0.1 & 0.8 & -2.2 \\
\hline measurement 2 & -0.5 & 0.5 & -3 \\
\hline measurement 3 & -0.5 & 0.9 & -2.3 \\
\hline measurement 4 & -0.4 & 0.4 & -2.2 \\
\hline measurement 5 & 0.2 & 1.3 & -5.6 \\
\hline measurement 6 & -0.6 & 0.6 & -6.9 \\
\hline measurement 7 & -1 & -0.5 & -3.7 \\
\hline measurement 8 & -0.6 & -0.7 & 1.3 \\
\hline measurement 9 & -0.8 & -0.8 & -0.8 \\
\hline measurement 10 & -1.1 & -1.2 & -2.6 \\
\hline average & -0.54 & 0.13 & -2.8 \\
\hline minimum & -1.1 & -1.2 & -6.9 \\
\hline maximum & 0.2 & 1.3 & 1.3 \\
\hline
\end{tabular}

Passive houses are equipped with mechanical supply and exhaust ventilation. These systems should be sealed off during the pressurization test, since the supply and exhaust openings represent huge leaks that are not relevant for infiltration in the building envelope.

It's up to the test operator to decide where the ventilation system will be disconnected. This can be anywhere between the external air supply/exhaust and the local air vents in the rooms. Obviously, the test result includes leakage through the ducts from the air supply/exhaust up to the point where the seals for the test are applied. Tests on House 1 show that leaks between ventilation ductwork, heat exchanger, ventilation system and silencer are responsible for an additional $43,3 \mathrm{~m} 3 / \mathrm{h}$, or $17,6 \%$ of the total leakage when the ventilation system is not sealed off directly after the external air intake and discharge points.

These examples show how apparently small decisions can have an impact on the overall air leakage. This is especially true for passive houses, which have a very small air leakage and thus, although the change in absolute value of the leakage is modest, will show a huge relative difference when something in the building preparation or test procedure is changed. This makes comparing test results difficult when looking for seasonal variation or durability effects, especially when pressurization tests are not performed by the same operator.

\section{SEASONAL VARIATIONS}

\subsection{Literature}

Studies reporting seasonal variation are available in literature, but building methods and prevailing climate should be taken in mind when drawing conclusions. Persily performed multiple tests during one year on a house in Princeton (Persily, 1982). He noticed up to 30\% higher air leakage in the winter compared to the lowest measurement results in summer. Air humidity on the contrary, showed peaks in the hot, humid summers and very low values in de the dry, cold winters. Persily claims the moisture in the hot summer air results in a swelling of 
the wood. When the wood swells, small cracks and gaps in the construction disappear resulting in a lower air leakage.

Kim and Shaw measured a seasonal variation up to $20 \%$ when performing a similar study on two houses in Canada, with the lowest values appearing in winter (Kim and Shaw, 1986). One of these houses had an air leakage very similar to the air leakage in passive houses.

Dickinson and Feustel performed a study on 10 houses in three different climates (Dickinson and Feustel, 1986). Three houses were located in Truckee and showed a clear seasonal variation due to the extreme climate, with up to $45 \%$ higher leakage in summer, compared to the winter measurements. This variation is very similar for all three houses, although the highest variation occurs in the house with the highest air leakage and vice versa. The fact that winter measurements show lower values is mainly attributed to the presence of large quantities of snow on and around the building envelope.

\section{Measurement results}

During the period December 2012 - April 2013, multiple pressurization tests were performed on both passive houses every three weeks. The results show an increase in average air leakage over each single test day by $13 \%$ over the course of the 7 test days in house 1 . These results are shown in Figure 2.

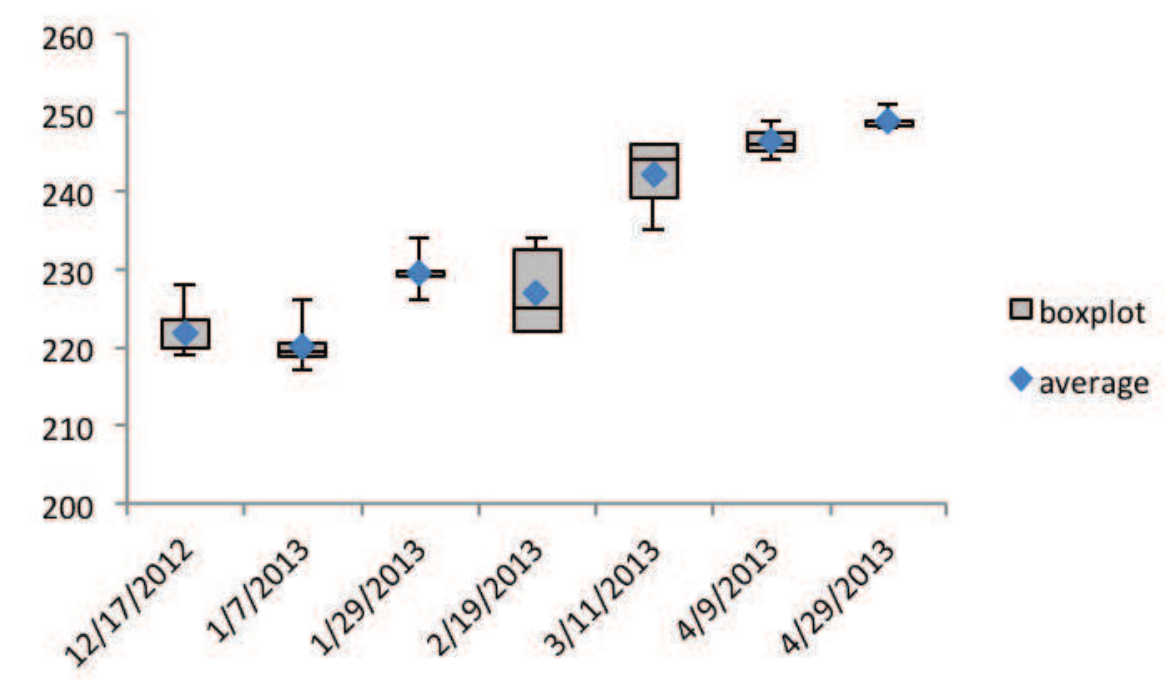

Figure 2. Boxplot and average of the leakage measured on 7 test days between December 2012 and April 2013 in house 1.

Although smaller in relative magnitude, this variation seems to follow the pattern found by Kim and Shaw (Kim and Shaw, 1986) or Dickinson and Feustel (Dickinson and Feustel, 1986). No substantial snowing occurred during the measurement period. The increase in leakage therefore has to be attributed to other factors. One potential mechanism is the differential thermal dilation of the masonry/concrete structure and the plaster that assures most of the airtightness. This would create fine cracks in the plaster, especially at edges and joints, leading to increased leakage. Another, more straightforward explanation might be a gradual deterioration of the air tightness of the ventilation ductwork due to repeated dismantling for the preparation of the pressurization test. 
The air leakage results of house 2 show no clear rising or declining trend. The results fluctuate around the average value, with a slight increase of $6 \%$ between the first and the last test day (Figure 3).

Although house 2 has a wood construction with wooden windows and doors and the Belgian climate creates a similar evolution in moisture content, it does not display the decreasing leakage in summer reported by Persily (Persily, 1982). In contrast to traditional wood frame construction, in passive houses such as this, all joints between wood panels and around envelope details such as windows etc. are sealed with tape. As these joints already are airtight, the swelling of wooden elements can't make them more airtight.

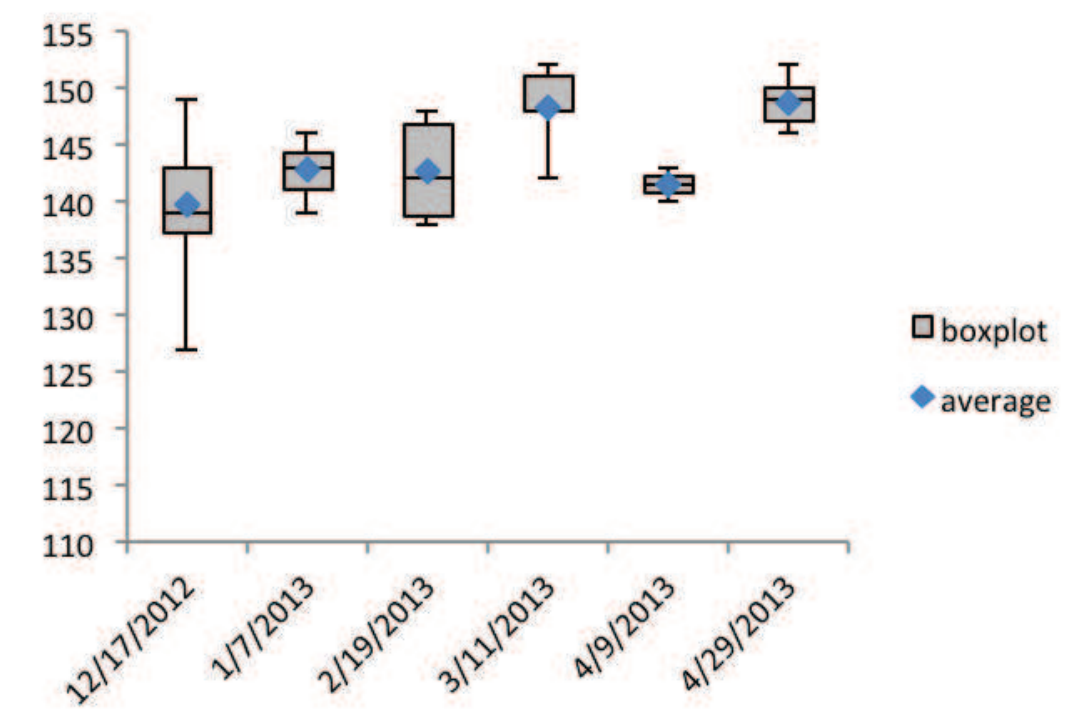

Figure 3. Boxplot and average of the leakage measured on 6 test days between December 2012 and April 2013 in house 2.

\section{LEAKAGE DURABILITY}




\subsection{Literature}

Some studies cover groups of buildings, which have been tested and retested after some years to evaluate the durability of airtightness. Due to the variation of building techniques and materials, conclusions are hard to draw. It's essential to make sure no interventions that may affect the airtightness were executed on the buildings between successive pressurization tests. Lux tested a group of 30 relatively airtight (ACH50 $<3,0 \mathrm{~h}-1$ ) houses six years after the original tests were carried out (Lux, 1987).

Only five houses were withheld, in which no interventions were performed. The evolution of the air leakage varies greatly, the maximum increase measured was $32 \%$ but one of the houses became $9 \%$ more airtight.

Proskiw and Eng performed tests on a group of 24 houses over a period of three years (Proskiw and Eng, 1997). The houses were on average five years old at the start of the test. Although the biggest evolution in airtightness is expected the first years after construction, Proskiw and Eng measured a maximum increase in air tightness of $37 \%$ and a $30 \%$ decrease over this period. The leakage of a group of houses with a PE airtightness barrier increased by $3 \%$ on average, while a group with a drywall airtightness barrier increased by $7 \%$.

Reiß and Erhorn compared the air leakage of 52 passive houses after construction and after a two-year period (Reiß and Erhorn, 2003). They reported an average 30\% increase, which seems dramatic but corresponds to an increase of the $\mathrm{ACH}_{50}$ by 0,09 . Increases in leakage rate as high as $216 \%$ were seen, but a few houses also showed a decrease up to $39 \%$.

\subsection{Measurement results}

Pressurization tests were performed on two estates of similar passive houses in Temse and Bredene, Belgium. The results of these tests were compared to the original test reports, generated from pressurization tests performed on completion of the dwellings one or two years earlier. No specific interventions on the dwellings occurred, making the results representative for normal wear and tear of the construction.

Eight houses were tested in Temse, as reported in Table 3, showing an average increase in air leakage by $29 \%$._Seven tests were performed in Bredene (Table 4.), showing an average increase of $45 \%$ in air leakage. A few extreme values are responsible for this high increase. The median of $25 \%$ might be a more representative value for the increase in air leakage. Some tests were probably not performed using the same building preparation as the original tests. It's not clear whether all doors were locked during the original tests and the sealing of the ventilation system might not have been executed in exactly the same way as during the original pressurization tests. As discussed in Paragraph 2, these 'small' differences can have a serious relative impact on air leakage. This makes qualifying the individual evolutions in air tightness very difficult. Despite these uncertainties, it seems clear that there is an increase in air leakage over the years, of an order in line with findings reported in literature. Similar leaks around the doors and service penetrations in the roofs were detected in Bredene as in Temse. These leaks seem to be responsible for a good part of the measured increase.

Table 3. measured evolution in leakage rates in Temse

\begin{tabular}{|r|r|r|r|r|r|r|}
\hline & $\mathrm{ACH}_{50}(-) 1$ & $\mathrm{ACH}_{50}(-)$ 2 & $\begin{array}{l}\text { Timespan } \\
\text { (month) }\end{array}$ & \multicolumn{1}{|l|}{$\Delta_{\text {depress. }}(\%)$} & $\Delta_{\text {press. }}(\%)$ & $\Delta_{\text {average }}(\%)$ \\
\hline house 1 & 0.43 & 0.56 & 19 & 30 & 35 & 32 \\
\hline house 2 & 0.55 & 0.81 & 21 & 38 & 55 & 47 \\
\hline house 3 & 0.56 & 0.54 & 13 & 2 & -9 & -3 \\
\hline house 4 & 0.33 & 0.43 & 13 & 26 & 34 & 30 \\
\hline house 5 & 0.5 & 0.68 & 13 & 33 & 36 & 34 \\
\hline house 6 & 0.59 & 0.82 & 19 & 38 & 42 & 40 \\
\hline
\end{tabular}




\begin{tabular}{|c|c|c|c|c|c|c|}
\hline house 7 & 0.44 & 0.56 & 13 & 23 & 27 & 25 \\
\hline house 8 & 0.46 & 0.64 & 18 & 30 & 30 & 30 \\
\hline mean & 0.48 & 0.63 & 16 & 28 & 31 & 29 \\
\hline median & 0.48 & 0.60 & - & 30 & 35 & 31 \\
\hline stdev (\%) & 18 & 22 & - & - & - & - \\
\hline $\max \operatorname{var}(\%)$ & 54 & 62 & - & - & - & - \\
\hline
\end{tabular}

Table 4. measured evolution in leakage rates in Bredene

\begin{tabular}{|c|c|c|c|c|c|c|}
\hline & $\mathrm{ACH}_{50}(-) 1$ & $\mathrm{ACH}_{50}(-) 2$ & $\begin{array}{l}\text { timespan } \\
\text { (months) }\end{array}$ & $\Delta_{\text {depress. }}(\%)$ & $\Delta_{\text {press. }}(\%)$ & $\Delta_{\text {average }}(\%)$ \\
\hline house 1 & 0.41 & 0.51 & 5 & 43 & 10 & 25 \\
\hline house 2 & 0.58 & 0.68 & 3 & 14 & 24 & 19 \\
\hline house 3 & 0.59 & 0.69 & 14 & 23 & 10 & 17 \\
\hline house 4 & 0.41 & 0.75 & 9 & 115 & 56 & 86 \\
\hline house 5 & 0.5 & 0.64 & 15 & 21 & 32 & 27 \\
\hline house 6 & 0.34 & 0.75 & 19 & 127 & 114 & 120 \\
\hline house 7 & 0.6 & 0.73 & 27 & 21 & 21 & 21 \\
\hline mean & 0.49 & 0.68 & 13 & 52 & 38 & 45 \\
\hline median & 0.50 & 0.69 & - & 23 & 24 & 25 \\
\hline stdev (\%) & 21 & 12 & - & - & - & - \\
\hline $\max \operatorname{var}(\%)$ & 53 & 35 & - & - & - & - \\
\hline
\end{tabular}

The super isolating doors might suffer from high temperature differences, which cause the door to warp. These slightly warped doors create leaks at the upper and lower parts of the doors. Reinforced doors might tackle this problem. The leaks surrounding roof penetrations can be avoided by using custom airtight sockets or top hat sleeves. Not that, although considerable relative deteriorations are found, in absolute terms, the buildings remain extremely airtight.

\section{WORKMANSHIP REPRODUCIBILITY}

Since the dwellings in Bredene and Temse are virtually identical, the results reported above also allow to assess the reproducibility of the leakage level achieved by the used construction method and workmanship. All houses in both case studies have masonry and concrete building envelopes, with PVC window frames and a wood frame roof construction. The air barrier of the building envelope is plaster, while for the roof a poly-ethylene membrane is used.

The results from these measurements are compared to those of a similar case study in Kortrijk in Figure 4 (Laverge et al., 2010). The Kortrijk case study consists of 29 identical houses built according to standard Belgian construction methods, which is very similar to the construction of the passive houses, but without specific attention to air tightness. The variance coefficients go down from $28 \%$ in the Kortrijk case to $12 \%$ in Bredene. Since only passive houses are included in the measurements in Temse and Bredene and this requires a maximum leakage level of $0.6 \mathrm{ACH}_{50}$, outliers will not appear in these samples. Nevertheless, the progress in reproducibility is remarkable. Note that, although vastly improved, the reproducibility of the workmanship is still far below that of the leakage test itself, the variance coefficient of which is around 0.025 (Delmotte and Laverge, 2011). 


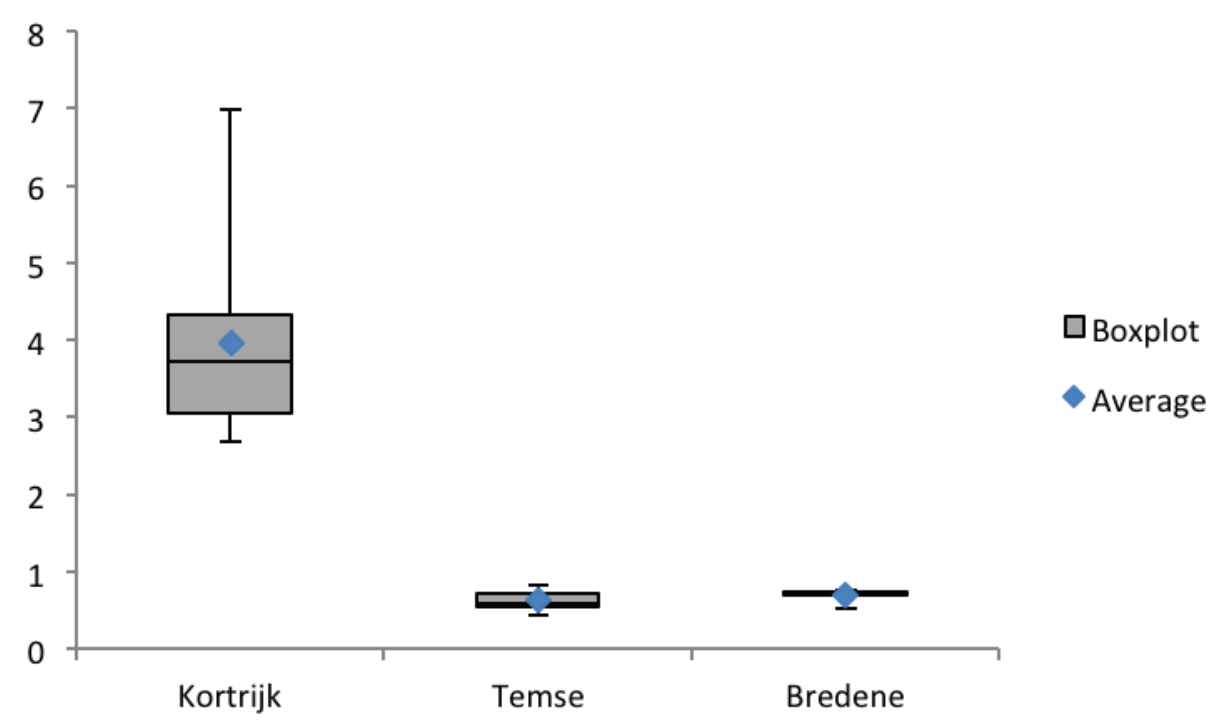

Figure 4. Boxplot of the leakage level $\left(\mathrm{ACH}_{50}\right)$ for the cases from 4 different case studies of quasi identical houses ( $\mathrm{N}=29,8$ and 7 respectively)

\section{CONCLUSIONS}

In this paper, 4 aspects of building leakage in extremely airtight houses are studied: the repeatability and reproducibility of the fan pressurization method, the impact of climate conditions on the measurements, the impact of the age of the construction and the reproducibility of the airtightness level in repeated construction of virtually identical houses. The leakage levels of the houses included in the tests are in the $10^{\text {th }}$ percentile of those included in the official Belgian energy performance database.

The results show similar relative repeatability and reproducibility intervals to those found in literature. The rather large effects of climate conditions reported in previous studies could not be reproduced. Normal wear and tear due to occupation of the dwelling proved to introduce substantial relative deterioration of the airtightness of the building shell (20-100\% increase in leakage), although in absolute values, the additional leaks were modest and the buildings remained very airtight. The reproducibility of the workmanship in extremely airtight construction proved better than that found in standard construction.

In general, we conclude that pressurization tests render robust results in extremely tight construction, but with respect to ambitious leakage limits, test conditions and small details such as the locking of window hardware can easily determine whether the dwelling will pass or fail.

\section{REFERENCES}

2013. Bijkomende specificaties voor de meting van de luchtdichtheid van gebouwen in het kader van de EPB-regelgeving (in Dutch), In: Overheid, V. (ed), Brussels, 16.

Cen. 2001. Thermal performance of buildings - Determination of air permeability of buildings - Fan pressurization method (ISO 9972:1996, modified), CEN.

De Baets K. and Jonckheere T. 2013. Cijferraport energieprestatieregelgeving: Procedures, resultaten en energetische karakteristieken van het Vlaamse gebouwenbestand periode 2006 - 2012 (in Dutch), Brussel, VEA, 51.

Delmotte C. and Laverge J. 2011. Interlaboratory tests for the determination of repeatability and reproducibility of buildings airtightness measuremetnts, 32nd AIVC conference 
and 1st TightVent Conference: Towards Optimal Airtightness Performance, Brussels, 9.

Dickinson J.B. and Feustel H.E. 1986. Seasonal variations in effective leakage area, Thermal performance of the exterior envelopes of buildings III, Atlanta, ASHRAE, 144-160.

Kim A.K. and Shaw C.Y. 1986. Seasonal variation in airtightness of two detached houses., Measured Air Leakage of Buildings., National Research Council Canada (NRC).

Laverge J. et al. 2010. Airtightness assessment of newly build single family houses in Belgium. In: Proceedings of Buildair 2010, pp. 8.

Lux M.E. 1987. time dependent changes in air leakage of low energy houses having sealed vapour retarders, National Research Council Canada, 25.

Murphy W. et al. 1991. A round robin test of Fan Pressurization Devices, Vol. RP-594, ASHRAE.

Persily A. 1982. Repeatability and Accuracy of Pressurization Testing, ASHRAE/DOE Conference on Thermal Performance of the Exterior Envelope of Buildings.

Proskiw G. and Eng P. 1997. Variations in Airtightness of Houses Constructed with Polyethylene and ADA Air Barrier Systems Over a Three-Year Period, Journal of Building Physics, 20, 278-296.

Reiß J. and Erhorn H. 2003. Messtechnische Validierung des Energiekonzeptes einer großtechnischen umgesetzten Passivhausentwicklung in Stuttgart-Feuerbach, Fraunhofer Institute for Building Physics, 132. 